\section{Journal of Obesity \& Metabolic Syndrome: A Platform for Acquiring and Disseminating the Most Recent Research Findings and Developing Research Concepts about Obesity}

\author{
Soo Lim* \\ Editor in Chief, Journal of Obesity \& Metabolic Syndrome \\ Department of Internal Medicine, Seoul National University Bundang Hospital, Seoul National University \\ College of Medicine, Seongnam, Korea
}

Received November 16, 2020

Reviewed December 3, 2020

Accepted December 3, 2020

*Corresponding author

Soo Lim

https://orcid.org/0000-0002-4137-1671

Department of Internal Medicine, Seoul National University Bundang Hospital, Seoul National University College of Medicine, 82 Gumi-ro 173beon-gil, Bundang-gu, Seongnam 13620, Korea

Tel: +82-31-787-7035

Fax: +82-31-787-4051

E-mail:limsoo@snu.ac.kr
The prevalence of obesity is increasing worldwide. ${ }^{1,2}$ Upward trends in the prevalence rates of general and abdominal obesity have been observed among both sexes and nearly all age groups. The prevalence of such obesity patterns is higher among individuals with lower education and household income levels. ${ }^{3,4}$ In a survey performed in 11 countries with a total of 14,502 people with obesity and 2,785 healthcare providers, $68 \%$ of the former and $88 \%$ of the latter agreed that obesity is a disease. Half of all respondents were concerned about the impact of excess weight on health. ${ }^{5}$ However, there was a 6-year gap between the time people with obesity began struggling with their excess weight or obesity and when they first discussed this with healthcare providers. These data support a need to increase understanding of obesity and improve education concerning its physiological basis and clinical management. In South Korea, from 2009 to 2018, the prevalence of general and abdominal obesity increased to $35.7 \%$ and $23.8 \%$, respectively. ${ }^{6}$ In a recent paper that investigated the perceptions, attitudes, behaviors, and barriers to effective obesity care in South Korea, we found that people with obesity in South Korea are motivated to lose weight and have expressed interest in healthcare providers being more active in their weight management. ${ }^{7}$ In this situation, a scientific platform to acquire and disseminate relevant knowledge about obesity is needed.

The Journal of Obesity \& Metabolic Syndrome is the official, peerreviewed research journal published of the Korean Society for the Study of Obesity (https://www.jomes.org/main.html). The abbreviated title is J Obes Metab Syndr or JOMES. The aim of JOMES is to contribute to a better understanding, prevention, and treatment of obesity to improve the lives of those affected, and thereby help reduce the incidence of obesity-related metabolic disorders. As Editor in Chief, I hope that JOMES can contribute to the cure and education of obesity through the sharing of scientific information on the latest developments in obesity among the many international societies dealing with this disorder.

JOMES covers multidisciplinary aspects of obesity, particularly its epidemiology, including prevalence and characteristics, etiology, diagnosis, pathophysiology, and management and treatments such as lifestyle modifications and pharmacological therapies. I passionately believe that JOMES is helping to increase knowledge about obesity and is inspiring confidence in the dedication of physicians and scientists to dealing with it.

According to initial reports, old age, hypertension, preexisting 
cardiovascular diseases, and obesity are considered as significant risk factors for the acquisition of coronavirus disease 2019 (COVID-19). ${ }^{8}$ Thus, the severity of COVID-19 is strongly associated with diabetes mellitus. ${ }^{9}$ During the COVID-19 pandemic, the decrease in physical activity and an increase in sedentary time caused by quarantine measures such as social distancing and lockdowns should be a source of concern in terms of the increased risk of obesity. Access to a healthy diet for all is also an issue, and these factors in turn are likely to contribute to gaining weight and metabolic impairments. ${ }^{10}$ In this critical period, all scientific bodies should provide a list of recommended open sources for the promotion of physical activity/exercise and healthy eating to mitigate developing obesity. With JOMES editorial team members, we have published an important paper in JOMES on how to manage obesity during the COVID-19 pandemic, ${ }^{11}$ which has become one of the journal's most widely read articles. Another most frequently read article is a paper on guidelines for managing obesity in Korea. ${ }^{12}$

JOMES was launched in 1992 and diverse studies on obesity were published under the title of the Journal of Korean Society for the Study of Obesity until 2004. From 2005 to 2016, its title was the Korean Journal of Obesity (pISSN 2383-899X, eISSN 2234-7631), and since 2017 (volume 26), the title is the Journal of Obesity \& Metabolic Syndrome. The journal is published quarterly on March 30, June 30, September 30, and December 30. Index words from the medical subject headings (MeSH) list of Index Medicus (https:// www.ncbi.nlm.nih.gov/mesh) are included in each article to facilitate article search.

JOMES was indexed in the Emerging Sources Citation Index (ESCI) in 2019, Scopus in 2019, and in PubMed and PubMed Central in 2019. We submitted the journal to be covered by Medline in 2019, but it was rejected because of the low volume of material. It was noted that the number of papers in JOMES was much lower than expected for a journal covering a major health issue for an entire country. In response to this comment, we have increased the number of papers in each issue to 12 or 13 from the first issue of 2020. The JOMES editorial team will reapply to Medline in 2022 and I hope that our journal will be listed there soon. Regarding the ESCI, I believe that it will be listed officially at SCI extended (SCIE) in 2021 and I trust that it will receive a high SCIE impact factor. Based on present calculations, the estimated SCIE impact factor for the journal will be 2.073 .

Taken together, all of the articles of this journal are now included in the indexes of ESCI, Scopus, PubMed, PubMed Central, DOAJ, Ebsco, KCI, KoreaMed, KoMCI, Science Central, Crossref Metadata Search, and Google Scholar. The journal is also published on the official website of the Journal of Obesity \& Metabolic Syndrome (https://www.jomes.org) and is widely distributed not only to physicians, scientists, nutritionist, dietitians, exercise physiologists, and nurses, but also to many institutions, libraries, and scientific societies. Our readership is now being expanded to many positions: researchers who are involved in research about obesity and obesityrelated diseases; clinicians or healthcare professionals who are responsible for the management of people with obesity; policy makers who desire access to recent information concerning the care of obesity and obesity-related metabolic disorders and aim to apply it in nationwide healthcare policies; medical students, residents, and fellows who can learn about the recent trends in the field and read about interesting cases; schoolteachers who want access to and can use various educational medical data; and the general public who are interested in scientific knowledge concerning obesity and obesity-related metabolic diseases.

Our journal publishes Open Access articles distributed under the terms of the Creative Commons Attribution NonCommercial License (http://creativecommons.org/licenses/by-nc/4.0/), which permits unrestricted noncommercial use, distribution, and reproduction in any medium, provided the original work is cited properly. It can be accessed from PubMed Central (https://www.ncbi. nlm.nih.gov/pmc/journals/3611/). Importantly, the journal does not accept any commercial product advertisements under the present policy. Journal propagation is carried out through the journal's website and distribution of an introduction pamphlet.

I commenced my duty as Editor in Chief of JOMES in 2017. In my first editorial, I promised that this new beginning with the journal would help maintain academic standards and take the lead in the development of the fields of obesity and metabolic syndrome. ${ }^{13}$ I have made efforts to improve the standards in terms of the editorial process and ethical guidelines under the Principles of Transparency and Best Practice in Scholarly Publishing, a Joint Statement by the Committee on Publication Ethics. I have also tried to improve the editorial process to ensure the timeliness of articles by 
simplifying the processes of reviewing, editing, and publishing. As noted, since 2017, JOMES has been indexed at many reputable official sites such as PubMed Central, in which I take pride. I believe that it will be accessed and referred to by many people more easily in the near future.

These advances were not possible without the help of our team of associate editors (Drs. Bo Kyung Koo, Ga Eun Nam, and Chang Hee Jung). I also thank Ms Ae Li Lee, the administrator of JOMES, for her invaluable assistance in editing manuscripts. Most of all, I would like to express my sincere thanks to Dr. Sun Huh, president of the Korean Association of Medical Journal Editors and the Korean Council of Science Editors, for his supportive guidance to the future direction of JOMES. ${ }^{14}$ With their efforts, JOMES will become one of the most respected and useful journals in this academic area.

In 2020, the JOMES website and submission system have been updated. The function of browsing through the articles has been enhanced with metric information for the journal such as the numbers of journal hits, downloads, and cross-reference citations. This upgrade is increasing the numbers of website visitors, content downloads, and manuscript submission. The JOMES editorial team has focused on improving the journal to become an even more rigorous platform to meet the expectations of clinicians, researchers, policy makers, and readers in the areas of obesity research and management. I firmly believe that our journal will soon be indexed at SCIE and Medline.

\section{CONFLICTS OF INTEREST}

The author declares no conflict of interest.

\section{REFERENCES}

1. Hruby A, Hu FB. The epidemiology of obesity: a big picture. Pharmacoeconomics 2015;33:673-89.

2. Chooi YC, Ding C, Magkos F. The epidemiology of obesity. Metabolism 2019;92:6-10.

3. Monteiro CA, Moura EC, Conde WL, Popkin BM. Socioeconomic status and obesity in adult populations of developing countries: a review. Bull World Health Organ 2004;82:940-6.

4. Dinsa GD, Goryakin Y, Fumagalli E, Suhrcke M. Obesity and socioeconomic status in developing countries: a systematic review. Obes Rev 2012;13:1067-79.

5. Caterson ID, Alfadda AA, Auerbach P, Coutinho W, Cuevas A, Dicker $D$, et al. Gaps to bridge: misalignment between perception, reality and actions in obesity. Diabetes Obes Metab 2019; 21:1914-24.

6. Nam GE, Kim YH, Han K, Jung JH, Rhee EJ, Lee SS, et al. Obesity Fact Sheet in Korea, 2019: prevalence of obesity and abdominal obesity from 2009 to 2018 and social factors. J Obes Metab Syndr 2020;29:124-32.

7. Lim S, Oh B, Lee SH, Kim YH, Ha Y, Kang JH. Perceptions, attitudes, behaviors, and barriers to effective obesity care in South Korea: results from the ACTION-IO study. J Obes Metab Syndr 2020;29:133-42.

8. Goyal P, Choi JJ, Pinheiro LC, Schenck EJ, Chen R, Jabri A, et al. Clinical characteristics of Covid-19 in New York City. N Engl J Med 2020;382:2372-4.

9. Lim S, Bae JH, Kwon HS, Nauck MA. COVID-19 and diabetes mellitus: from pathophysiology to clinical management. Nat Rev Endocrinol 2021;17:11-30.

10. Lim S, Lim H, Despres JP. Collateral damage of the COVID-19 pandemic on nutritional quality and physical activity: perspective from South Korea. Obesity (Silver Spring) 2020;28:178890.

11. Lim S, Shin SM, Nam GE, Jung CH, Koo BK. Proper management of people with obesity during the COVID-19 pandemic. J Obes Metab Syndr 2020;29:84-98.

12. Seo MH, Lee WY, Kim SS, Kang JH, Kang JH, Kim KK, et al. 2018 Korean Society for the Study of Obesity Guideline for the management of obesity in Korea. J Obes Metab Syndr 2019;28:40-5.

13. Lim S. Journal of Obesity \& Metabolic Syndrome: a new international journal targeting the pathophysiology and treatment of obesity and metabolic syndrome. J Obes Metab Syndr 2017;26:81-3.

14. Huh S. Journal statistics, coping strategy with upcoming scholarly journal publishing environment including Plan-S, and appreciation for reviewers and volunteers. J Educ Eval Health Prof 2019;16:41. 